\title{
Toward Mindsponge-ism: institutionalizing information processing in an efficient and healthy manner
}

\author{
Hong-Kong T. Nguyen \\ Manh-Tung Ho
}

A.I. for Social Data Lab (AISDL), Vuong \& Associates,

Hanoi, 100000, Vietnam

February 12, 2021

In a world saturated with information and misinformation, and in a time clouded by anxiety and insecurity due to an on-going pandemic, it is difficult to stay afloat and make sense of everything around us. Yet, just because it is difficult does not mean that it is impossible. To find and obtain information that is accurate, relevant, up-to-date, and insightful requires a special kind of attention and training. To that end, this essay suggests the need to build and nurture a healthy culture of information processing. One particular approach is to draw from the multi-filtering system of the mindsponge mechanism (Vuong, 2016; Vuong \& Napier, 2015), the adoption of which could potentially move us toward a more permanent way of thinking and living: "mindsponge-ism." 
At the heart of the mindsponge mechanism lies its multiple layers of information domains and filters, all of which operate around an individual's core mindset. Here, information is used in the broadest sense possible for it may be values, beliefs, ideas, or any bit of abstraction that emerges in one's mind. Just as how a sponge is capable of quickly absorbing water as well as sloshing water right back out, the mind can train itself to behave in an equally efficient manner. The thinking supplements existing quantitative tools in information theory for it lays out an underlying framework of human information processing, prior to engagements in complex communication structures (Lynn, Papadopoulos, Kahn, \& Bassett, 2020).

While the proposition of "mindsponge" is intuitive, if not to say straightforward, its explanatory power is promising. It is highly applicable for theorizing on the formation and ejection of ideas and values, such as how people of a certain culture come to adopt specific cultural values and beliefs (Vuong et al., 2018), how certain human behaviors endure despite their glaring contradictions (La \& Vuong, 2019; Vuong et al., 2020), or even how suicidal ideation arises and persists in a person's mind (Nguyen et al., 2021). Understanding the mindsponge mechanism means one needs to let go of the alluring simplistic binary view of the human mind such as the tendency to view a moral decision as either deontological or utilitarian (Greene, 2013), or to categorize thinking style into either holistic or analytical (Henrich, 2020). Rather, the mindsponge model invites a person to view the mind as a core-and-periphery system, where values and ideas engage in a selection process to stay near the core via the inductive attitude. Thus, even conflicting ideas and values can "cooperate" and co-exist as long as their combination serves the host. This mode of explaining the activities of the human mind is particularly valuable in today's fragmented news and social media culture. 


\section{References}

Greene, J. (2013). Moral Tribes: Emotion, Reason, and the Gap Between Us and Them. New York: Penguin Press.

Henrich, J. (2020). The WEIRDest people in the world: How the West became psychologically peculiar and particularly prosperous. London: Farrar, Straus and Giroux.

La, V.-P., \& Vuong, Q.-H. (2019). bayesvl: Visually Learning the Graphical Structure of Bayesian Networks and Performing MCMC with 'Stan.' The Comprehensive R Archive Network (CRAN). Retrieved from <https://cran.rproject.org/web/packages/bayesvl/index.html>; version 0.8.5 (officialy published on May 24, 2019).

Lynn, C. W., Papadopoulos, L., Kahn, A. E., \& Bassett, D. S. (2020). Human information processing in complex networks. Nature Physics, 16(9), 965-973. doi:10.1038/s41567020-0924-7

Nguyen, M.-H., Le, T. T., Nguyen, H.-K. T., Ho, M.-T., Huyen, N. T. T., \& Vuong, Q.-H. (2021). Alice in Suicideland: Exploring the Suicidal Ideation Mechanism Through Social Connectedness and Help-seeking Behaviors. PsyArXiv.

Vuong, Q.-H. (2016). Global mindset as the integration of emerging socio-cultural values through mindsponge processes: A transition economy perspective. In J. Kuada (Ed.), Global Mindsets (pp. 123-140): Routledge.

Vuong, Q.-H., Bui, Q.-K., La, V.-P., Vuong, T.-T., Nguyen, V.-H. T., Ho, M.-T., . . Ho, M.-T. (2018). Cultural additivity: behavioural insights from the interaction of Confucianism, Buddhism and Taoism in folktales. Palgrave Communications, 4(1), 143. doi:10.1057/s41599-018-0189-2 
Vuong, Q.-H., Ho, M.-T., Nguyen, H.-K. T., Vuong, T.-T., Tran, T., Hoang, K.-L., . . La, V.-P. (2020). On how religions could accidentally incite lies and violence: folktales as a cultural transmitter. Palgrave Communications, 6(1), 82. doi:10.1057/s41599-020-0442-3

Vuong, Q.-H., \& Napier, N. K. (2015). Acculturation and global mindsponge: An emerging market perspective. International Journal of Intercultural Relations, 49, 354-367. doi:10.1016/j.ijintrel.2015.06.003 